Journal of Social Sciences 1 (4): 243-245, 2005

ISSN 1549-365

(c) 2005 Science Publications

\title{
The Applicability of the Short-run Phillips curve to Namibia
}

\author{
Cyril A. Ogbokor \\ Polytechnic of Namibia, P. M. B. 13388, Windhoek, Namibia
}

\begin{abstract}
In this research, we invoke linear and logarithmic regression models to empirically test the validity of the Short-run Phillips curve for Namibia by relying on macroeconomic time-series data running from 1991 to 2005.Our results offer some support for the presence of the phenomenon of stagflation in Namibia. This is rather contradictory to the underlying philosophy of the original Phillips curve. In the light of the outcome of the investigation anti-inflation cum unemployment measures are suggested. Further studies focussing on the applicability of the Phillips curve to the economy of Namibia is strongly recommended.
\end{abstract}

Key words: Phillips curve, inflation, unemployment, time-series data, regression method, Namibia

\section{INTRODUCTION}

The Phillips curve represents one of the most surprising discoveries and controversial relationships in economic literature. In 1958 Phillips $^{[1]}$ using data based on the United Kingdom for the years 1861 to 1957 tried to investigate the relationship between unemployment rates and changes in wage rates. Although the original version of the Phillips curve relates the rate of increase of wages to unemployment, subsequent studies have substituted wages with inflation. The result of the Phillips's investigation gave rise to one of the most famous curves in economics.

The Phillips curve can be interpreted as a trade-off between inflation and unemployment. It suggested that policymakers could choose different combinations of unemployment and inflation. For instance, they could have low unemployment as long as they are prepared to accept high inflation and vice versa. The Phillips curve was very popular in the 1960s but fell apart afterwards. This is so because observed data for the 1970s as well as the 1980s for some economies like Britain and the United States of America contradicted the notion of the Phillips curve, Dornbusch, Fischer and Startz ${ }^{[2]}$. Besides, the two oil price shocks of 1973-1974 and $1979-1980^{[3]}$, which resulted in periods of increased inflation that were not associated with falling unemployment provoked scholars to further question the stability as well as the relevance of the Phillips curve.

In a similar fashion, Phelps ${ }^{[4]}$ in his investigation of "Phillips curve, Expectations of Inflation and Optimal Employment over Time" observed that inflation and unemployment actually have the tendency to move in the same direction. Also, Friedman ${ }^{[5]}$ in his study concerning monetary policy arrived at a result not fundamentally different from that of Phelps. The outcome of the studies of Phelps and Friedman led to the recognition of the existence of a simultaneous increase in inflation and unemployment technically described as stagflation in economic literature. Other studies reviewed Lucas and Rapping ${ }^{[6]}$; and Samuelson ${ }^{[7]}$ also attested to the existence of the phenomenon of stagflation in major industrialised economies. Furthermore, other literature reviewed Haydam $^{[8]}$ and Burda et al. ${ }^{[9]}$ acceded to the presence of the Phillips curve relationship, at least, in the short-run. In a nutshell, while several empirical studies appear to accede to the existence of the Phillips curve at least in the short-run, others have expressed doubts over the stability of this relationship in the long run in the face of stagflation.

Against this background, the driving objective of this study is to estimate the short-run Phillips curve for Namibia using macroeconomic data running from 1991 to 2005 .

\section{MATERIALS AND METHODS}

Data sources and research procedure: The method of Ordinary Least Squares [OLS] was used to examine the relationship between inflation and unemployment in Namibia within the framework of the Phillips curve. In order to estimate the various equations utilised for the purpose of the study, we have used time-series data covering the period 1991 to 2005 . The basic set of data relied upon were obtained from the various publications of the Central Bank of Namibia and those of the 
National Planning Commission of Namibia. Interpolation and extrapolation techniques were also resorted to in order to simulate missing data for the years that were not readily available in the various publications used for the collation of the data for this research.

Model formulation and specification: Recall that the economic issue tested in the study is to try and establish a short-run relationship between the rate of inflation and the level of unemployment for the economy of Namibia within the framework of the Phillips curve. In the light of this, we defined the variables to be used in this study in the following manner:

Let $\operatorname{Inf}_{\mathrm{t}}=$ annual inflation rate [\%]

and $\mathrm{Une}_{\mathrm{t}}=$ annual unemployment rate [\%]

In a general functional model, we can assume that

$\operatorname{Inf}=\mathrm{f}($ Une $)$

Where:

Inf $=$ Inflation rate

Une $=$ Unemployment variable

$\mathrm{t}=$ Time period

By taking the derivative of the above functional model with respect to unemployment, we expect the following result:

$\partial$ (Inf)

$\partial(------<0$

$\partial$ (Une)

suggesting that inflation and unemployment are negatively related.

In the light of this, the following linear and logarithmic regression equations were derived and estimated:

1. $\operatorname{Inf}=\mathrm{A}_{\mathrm{o}}+\mathrm{A}_{1}$ Une

2. Une $=\mathrm{A}_{\mathrm{o}}+\mathrm{A}_{1} \mathrm{Inf}$

3. $\operatorname{LnInf}=\mathrm{A}_{\mathrm{o}}+\mathrm{A}_{1}$ LnUne

4. LnUne $=\mathrm{A}_{\mathrm{o}}+\mathrm{A}_{1}$ LnInf

\section{RESULTS AND DISCUSSION}

This study invoked linear and logarithmic regression models to estimate the Phillips curve for the economy of Namibia. The use of the asterisk symbol $\left(^{*}\right)$ implies that the variable is significant at $5 \%$ level. The Correlation Coefficient (R) measures the extent to which inflation and unemployment move together. The Coefficient of Determination $\left(\mathrm{R}^{2}\right)$ indicates how well the model performs. More specifically, it shows the extent to which the explanatory variables taken together are able to account for a systematic variation in the regressand. The Durbin-Watson (D-W) statistic is used to test for the presence of autocorrelation in the estimated models. It is a measure of correlation between the residuals. The t-statistic enables us to test the null hypothesis that the coefficient of the regressor is zero, that is, the regressor does not contribute to predicting the regressand. The estimated equations and results generated in this study are presented and subsequently discussed in the following sequence:

$$
\begin{gathered}
\text { 1. } \mathrm{Inf}=-26.289+1.063 \text { Une } \\
(-0.737) \quad(0.989) \\
\mathrm{R}=0.265 \quad \mathrm{R}^{2}=0.070 \quad \mathrm{D}-\mathrm{W}=0.974
\end{gathered}
$$

2. Une $=32.620+.06591 \mathrm{Inf}$

(51.085) (.989)

$\mathrm{R}=0.265 \quad \mathrm{R}^{2}=0.070 \quad \mathrm{D}-\mathrm{W}=1.089$

3. $\operatorname{LnInf}=-16.380+5.283 \mathrm{LnUne}$

$$
(-1.103)(1.246)
$$

$\mathrm{R}=0.327 \quad \mathrm{R}^{2}=0.107 \quad \mathrm{D}-\mathrm{W}=0.696$

4. LnUne $=3.460+.02021 \mathrm{LnInf}$

$$
\text { (98.734) (1.246) }
$$

$\mathrm{R}=0.327 \quad \mathrm{R}^{2}=0.107 \quad \mathrm{D}-\mathrm{W}=1.179$

All the coefficients of the predictors contained in the estimated equations 1 to 4 above are positively signed despite that none of them passes the significance test at 5\% level. The Correlation Coefficients in respect of the four equations are consistently positive suggesting that inflation and unemployment move in the same direction. The performance of the estimated model is quite unsatisfactory with the predictors accounting for only about 9\% of the systematic variation in the dependent variable. We also observed the absence of autocorrelation in equations 1,2 and 4, while equation 3 suffered from positive serial correlation.

It is evident from our results and discussion that the economy of Namibia does not conform to the traditional Phillips curve postulation. The Namibian economy rather exhibits the presence of stagflation. This is not far from the real situation. In the last eight years or so the Namibian economy has been simultaneously facing a high level of unemployment and inflation, mainly imported inflation. This calls for an appropriate macroeconomic policy response.

\section{CONCLUSION}

This investigation was concerned mainly with estimating the Short-run Phillips curve for the Namibian economy. We observed that contrary to the Phillips curve notion of an inverse relationship between inflation and unemployment, the Namibian economy is 
indeed experiencing a continual increase in both inflation and unemployment, a situation technically referred to as stagflation in the literature. It is therefore not possible to reduce inflation by simply opting for a higher dose of unemployment. From this analysis, we conclude that a favourable macroeconomic environment supported by strong structural reforms, including an aggressive export-driven industrialisation strategy should help to boost domestic production substantially, enhance employment activities and consequently control prices of goods and services.

We suggest that future studies on the applicability of the Phillips curve should include the other members of the Southern African Customs Union (SACU), namely, Botswana, Lesotho, Swaziland and the Republic of South Africa. Finally, it is expected that the outcome of this study would lead to further studies on the part of other professional colleagues regarding the issue under investigation.

\section{ACKNOWLEDGEMENT}

My profound gratitude goes to my beloved wife Gladys A. Ogbokor as well as my three children Efemena, Elo and Eloho for their encouragement, endurance and sacrifice. I am also highly indebted to the Rector of the Polytechnic of Namibia, Dr. Tjama Tjivikua and his management team for encouraging Applied Research. Finally, I wish to thank Camillus Mahindi of the Department of Statistics, University of Namibia for running the regression equations utilised in the study.

\section{REFERENCES}

1. Phillips, A.W., 1958. The relation between unemployment and the rate of change of money wages in the United Kingdom, 1861-1957. Economica, 25: 283-299.

2. Dornbusch, R., S. Fischer and R. Startz, 2001. Macroeconomics. McGraw-Hill, New York, pp: 103-107.

3. McConnell, C.R. and S.L. Brue, 2002. Economics: Principles, Problems and Policies. McGraw-Hill, New York, pp: 149.

4. Phelps, E.S., 1967. Phillips curves, expectations of inflation and optimal employment over time. Economica, 34: 254-281.

5. Friedman, M., 1968. The role of monetary policy. Am. Econ. Rev., 58: 1-17.

6. Lucas, R.E. and L.A. Rapping, 1969. Real wages, employment and inflation. J. Polit. Econ., 77: 721754.

7. Samuelson, P.A. and R.M. Solow, 1960. Analytical aspects of anti-inflation policy. Am. Econ. Rev., 50: 177-194.

8. Haydam, N., 2002. The principles of macroeconomics. Van Schaik, Pretoria, pp: 216-217.

9. Burda, M. and C. Wyplosz, 2001.Macroeconomics. Oxford University Press, New York, pp: 281-284. 